\title{
Estimated Stearoyl-CoA-desaturase (SCD)-1 and Elon- gase of Very Long Chain Fatty Acids (Elovl) 6 Activities From Serum Fatty Acids Are Reciprocally Associated with Visceral Fat Area in Type 2 Diabetic Patients
}

\author{
Shigeru Yatoh ${ }^{1 *}$, Kumiko Totsuka-Mizuma ${ }^{2}$, Takashi Matsuzaka ${ }^{1,3}$, Motohiro Sekiya ${ }^{1}$, Hiroaki Suzu- \\ ki $^{1,2}$, Hitoshi Shimano ${ }^{1,4,5,6}$ \\ ${ }^{1}$ Department of Internal Medicine (Endocrinology and Metabolism), Faculty of Medicine, University of Tsukuba, Tsukuba, Ibaraki, Japan \\ ${ }^{2}$ Department of Clinical Nutrittion, University of Tsukuba Hospital, Tsukuba, Ibaraki, Japan \\ ${ }^{3}$ Division of Energy Metabolism Research, Transborder Medical Research Center, University of Tsukuba, Tsukuba, Ibaraki, Japan \\ ${ }^{4}$ International Institute for Integrative Sleep Medicine (WPI-IIIS), University of Tsukuba, Tsukuba, Ibaraki, Japan. \\ ${ }^{5}$ Life Science Center for Survival Dynamics, Tsukuba Advanced Research Alliance (TARA), University of Tsukuba, Tsukuba, Ibaraki, Japan \\ ${ }^{6}$ Japan Agency for Medical Research and Development-Core Research for Evolutional Science and Technology (AMED-CREST), Chiyoda-ku, Tokyo, Japan
}

*Corresponding author: Shigeru Yatoh, Department of Internal Medicine (Endocrinology and Metabolism), Faculty of Medicine, University of Tsukuba, 1-1-1 Tennodai, Tsukuba, Ibaraki, 305-0031, Japan, Tel: +81-29-853-3053; Fax: +81-29-853-3174; E-mail: yatou-endo@umin.ac.jp

\begin{abstract}
:
Introduction: Abdominal visceral fat accumulation can cause insulin resistance in type 2 diabetic patients. We investigated the association between serum fatty acid levels and the visceral fat area (VFA).

Materials and methods: In this retrospective study we evaluated relationship between the serum levels of 24 fatty acids and the abdominal VFA measured by computed tomography in 32 patients with type 2 diabetes who had been hospitalized.

Results: Of the 24 fatty acids evaluated, the serum palmitoleic acid (C16:1 n-7) level had a moderate positive correlation ( $\mathrm{r}$ $=0.565)$ with VFA while the serum arachidic acid (C:20:0) level had a very weak negative correlation ( $\mathrm{r}=-0.351)$;no significant correlations with the VFA were found for the remaining 22 fatty acids. On the other hand, we discovered 5 significant correlations in 18 estimated activity indices of elongases and desaturases, which were calculated with ratios of corresponding fatty acid concentrations. The palmitoleic acid (C16:1 n-7)/palmitic acid (C16:0) ( $\mathrm{r}=0.719$, stearoyl-CoA-desaturase (SCD)-1 (16)) index and the oleic acid (C18:1 n-9) / stearic acid (C18:0) (r=0.534, SCD-1(18) index had moderate to strong correlations with the VFA, whereas stearic acid (C18:0) /palmitic acid (C16:0) $(\mathrm{r}=-0.495$, elongase of very long chain fatty acids (Elovl) 6 index exhibited a significant negative correlation.

Conclusions: The serum palmitoleic acid (C16:1 n-7) level and some estimated activity indices significantly correlated with the VFA in the type 2 diabetic patients. SCD-1 indices and an Elovl6 index were reciprocally associated with the VFA. The SCD-1(16) index, which showed the strongest correlation with the VFA along with the negative association of the Elovl6 index, might be useful in estimating the VFA.
\end{abstract}

\section{Introduction}

Abdominal visceral fat accumulation can cause insulin resistance in persons with type 2 diabetes. We hypothesized that desaturase or elongase activities could reflect the visceral fat area (VFA), thus minimizing the need for measurements of the VFA by computed tomography. Because direct measurement of tissue desaturase activities is difficult in humans, surrogate measures of desaturase activity (estimated desaturase activities) have been frequently used in observational studies. Estimated D9- (or stearoyl-CoA-desaturase (SCD)-1), D6- and D5-desaturase activities have been associated with the percentage of body fat ${ }^{[1]}$, metabolic syndrome $^{[2]}$, myocardial infarction ${ }^{[3]}$ and improvements in insulin sensitivity after lifestyle interventions ${ }^{[4]}$.
Received Date: June 20, 2018

Accepted Date: July 11, 2018

Published Date: July 16, 2018

Citation: Yatoh, S., et al. Estimated Stearoyl-CoA-desaturase (SCD)-1 and Elongase of Very Long Chain Fatty Acids (Elovl) 6 Activities From Serum Fatty Acids Are Reciprocally Associated with Visceral Fat Area in Type 2 Diabetic Patients. (2018) J diab Obes 5(1): 41- 47.

Copyright: (C) 2018 Yatoh, S. This is an Open access article distributed under the terms of Creative Commons Attribution 4.0 International License. 
We have investigated roles of elongases and desaturases with regard to physiology and pathology in mice. We report$\mathrm{ed}^{[5]}$ that loss of elongase of very long chain fatty acids family member 6 (Elovl6) function reduced stearic acid (C18:0) and oleic acid (C18:1n-9) levels and increased palmitic acid (C16:0) and palmitoleic acid (C16:1n-7) levels and that mice with targeted disruption of Elovl6 were protected against development of hepatic insulin resistance when fed a high-fat/high-sucrose diet despite hepatosteatosis and obesity similar to the wild-type mice. This result suggested that hepatic fatty acid composition, particularly $\mathrm{C} 16: 0$ to $\mathrm{C} 18: 0$ conversion, was crucial for insulin sensitivity rather than lipid accumulation.

Elov16 belongs to an elongase family of microsomal enzymes and involves the elongation of saturated and monounsaturated fatty acids with 12, 14, 16 carbons, mainly converting $\mathrm{C} 16$ to $\mathrm{C} 18$. Elovl6 is also a gene target of sterol regulatory element-binding protein (SREBP)- 1, a crucial transcription factor for fatty acid synthesis, playing a role in both lipid and glucose metabolism ${ }^{[6,7]}$. Clinically, genetic variations in the Elovl6 gene have a significant association with insulin sensitivity in population-based studies ${ }^{[8,9]}$.

Furthermore, we revealed that Elovl6 knockout mice are markedly resistant to atherosclerosis and nonalcoholic steatohepatitis (NASH) presumably due to the altered fatty acid composition in the macrophages and liver, respectively ${ }^{[10,11]}$ Conversely, over expression of the Elovl6 gene promoted NASH in mouse models ${ }^{[12]}$. We also recognized the alteration of fatty acid composition regulated by Elovl6, involved various pathophysiologies in other tissues such as lung fibrosis, vascular smooth muscle cell proliferation following wire injury, and chondrocyte growth and differentiation ${ }^{[13-15]}$. Through these findings, we hypothesized fatty acid composition should associate with the pathology of obesity-related metabolic diseases in human.

In type 2 diabetic patients, visceral fat accumulation is known to be associated with and presumably induces insulin resistance. However, the association of visceral fat accumulation with particular desaturase or elongase activities, has not been fully revealed. Therefore, we investigated the association between the VFA and various surrogate indices of desaturases and elongases which were calculated from serum concentrations of fatty acids in type 2 diabetic patients.

\section{Materials and Methods}

\section{Study participants}

This retrospective study utilized data collected from inpatients who had been hospitalized in the Department of Endocrinology and Metabolism in University of Tsukuba Hospital between April 2009 and March 2012. Inclusion criteria were having type 2 diabetes, age $>20$ years, and having had an abdominal computed tomography (CT) scan and measurement of serum fatty acids during hospitalization. Exclusion criteria were liver cirrhosis, diabetic ketoacidosis, hyperosmolar hyperglycemic state, administration of eicosapentaenoic acid (C20:5 n-3) or adrenocortical hormones, emaciation (body mass index $<18.5 \mathrm{~kg} / \mathrm{m}^{2}$ ), and malnutrition.

We identified 32 patients who met the inclusion criteria and exclusion criteria (19 mean, 13 women). The following information and data were collected from their medical records: age, sex, body mass index, medical history, medications, glycated hemoglobin( $\mathrm{HbA} 1 \mathrm{c})$, and fasting concentrations of glucose, insulin, C-peptide, free fatty acids, triglycerides and total, low-density lipoprotein (LDL), and high-density lipoprotein (HDL) cholesterol. Existence or nonexistence of fatty liver was confirmed through the examination of reports of abdominal ultrasonography. Table 1 shows the characteristics of the study patients.

Table 1: Characteristics of study participants

\begin{tabular}{|l|l|}
\hline & Mean \pm SD \\
\hline Age $($ years $)$ & $60 \pm 14$ \\
\hline BMI $\left(\mathrm{kg} / \mathrm{m}^{2}\right)$ & $27.3 \pm 5.6$ \\
\hline VFA $\left(\mathrm{cm}^{2}\right)$ & $99.8 \pm 51.4$ \\
\hline HbAlc $(\%)$ & $9.6 \pm 1.9$ \\
\hline fasting blood test on the hospitalization & \\
\hline plasma glucose $(\mathrm{mg} / \mathrm{dl})$ & $172 \pm 67$ \\
\hline Insulin $(\mu \mathrm{U} / \mathrm{ml})$ & $10.9 \pm 20.4$ \\
\hline C-peptide $(\mathrm{ng} / \mathrm{ml})$ & $1.9 \pm 1.1$ \\
\hline T-cho $(\mathrm{mg} / \mathrm{dl})$ & $180 \pm 39$ \\
\hline TG $(\mathrm{mg} / \mathrm{dl})$ & $125 \pm 53$ \\
\hline HDL-C $(\mathrm{mg} / \mathrm{dl})$ & $47.6 \pm 9.5$ \\
\hline LDL-C $(\mathrm{mg} / \mathrm{dl})$ & $125 \pm 53$ \\
\hline FFA $(\mathrm{mEq} / \mathrm{l})$ & $0.69 \pm 0.32$ \\
\hline Medicines & rate \\
\hline statin & $34 \%$ \\
\hline fibrate & $3 \%$ \\
\hline EPA & $0 \%$ \\
\hline metformin & $44 \%$ \\
\hline pioglitazone & $6 \%$ \\
\hline DPP4 inhibitor & $6 \%$ \\
\hline insulin & $38 \%$ \\
\hline Fatty liver & $50 \%$ \\
\hline
\end{tabular}

BMI: body mass index

T-cho: total cholesterol

TG: triglycerides

HDL-C: high-density lipoprotein cholesterol

LDL-C: low-density lipoprotein cholesterol

FFA: free fatty acid

EPA: eicosapentaenoic acid

DPP-4: dipeptidyl peptidase-4

This study was approved by the University of Tsukuba ethics committee and was conducted according to the tenets of the Declaration of Helsinki (Protocol number: H24-25).

\section{Measurement of serum fatty acid concentrations}

Blood samples were collected before breakfast on the day following hospitalization. Serum fatty acid levels were analyzed at Mitsubishi Kagaku Medience Co. (Tokyo, Japan). Lipids were extracted from serum with chloroform and methanol under a nitrogen atmosphere and saponified with potassium hydroxide and ethanol. The lipids were transesterified to methyl esters of fatty acids with a boron fluoridemethanol reagent, benzene, and meth- 
anol. The methyl esters were analyzed in a HP 6890 gas chromatograph (Agilent, Santa Clara, CA, U.S.A.) equipped with a flame ionization detector. The identity of 24 individual fatty acid peaks was ascertained by comparing each peak's retention time to that of the retention times of fatty acids in synthetic standards of known fatty acid composition. A commercially available standard material (pentadecanoic acid; Tokyo Chemical Industry Co., Ltd., Tokyo, Japan) was used as an internal standard for fatty acid analysis. Each fatty acid concentration was expressed as microgram per milliliter $(\mu \mathrm{g} / \mathrm{ml})$ of total serum.

\section{Calculation of estimated activities of desaturase and elon- gase enzymes}

Long-chain fatty acids are synthesized through desaturation and elongation. Figure 1 shows the pathway of fatty acid synthesis. The 24 fatty acids measured in this study are designated by numbers in circles (1)-(24).

Desaturase and elongase activities were estimated as the ratio of product to the precursor of individual fatty acids in serum. For example, the ratio of (5) palmitoleic acid(C16:1n-7) to (4) palmitic acid (C16:0) indicates the estimated activity of $\Delta$-9-desaturase-16 (stearoyl-CoA desaturase-1 (16)) and the ratio (6) stearic acid(C18:0) to (4) palmitic acid(C16:0) indicates the estimated activity of Elovl6.

\section{Measurement of visceral fat area (VFA)}

VFA was measured by computed tomography imaging at the level of the navel using computer software (Fat Scan, East Japan Institute of Technology Co. Ltd., Ibaraki, Japan.).

\section{Statistical analysis}

Data are shown as mean $+/$ - standard deviation. Pearson correlation (IBM $®$ SPSS version 25, Japan IBM Co., Ltd., Tokyo, Japan) was used to analyze correlations with VFA.

\section{Results}

As shown in Table 1, patients were roughly profiled to be moderately obese and have poorly controlled type 2 diabetes at hospitalization despite of receiving metformin or insulin treatment, but without marked dyslipidemia. Half of the patients possessed fatty liver. VFA as measured by computed tomography was 99.8 $+/-51.4 \mathrm{~cm}^{2}$

Table 2 shows serum concentrations of 24 fatty acids in all study participants with marked numbers (1)-(24) provided forease of identification within tables and figures. Mean concentrations were above the normal ranges in eicosapentaenoic acid (C20:5 n-3, (17)), behenic acid (C22:0, 18), lignoceric acid (C24:0, (22), and nervonic acid (C24:1 n-9, (24)). Those of arachidic acid (C:20:0, (11)) and docosahexaenoic acid (C22:6 n-3 (23) were close to the high normal limits.

First, we analyzed the correlation between the VFA and concentration of each fatty acid (Table 3). Significant correlations with VFA were found for palmitoleic acid (C16:1 n-7, (5) $(\mathrm{r}=0.565, \mathrm{p}=0.001)$ and arachidic acid $(\mathrm{C}: 20: 0$, (11) $)(\mathrm{r}=$ $-0.351, \mathrm{p}=0.049)$.
Table 2: Concentrations of 24 fatty acids for all study participants

\begin{tabular}{|c|c|c|c|c|}
\hline & fatty acid & $\begin{array}{l}\text { abbrevia- } \\
\text { tion }\end{array}$ & Mean \pm SD & $\begin{array}{l}\text { normal } \\
\text { range }\end{array}$ \\
\hline (1) & lauric acid & $\mathrm{C} 12: 0$ & $4.1 \pm 1.7$ & -6.7 \\
\hline (2) & myristic acid & C14:0 & $19.2 \pm 8.5$ & $10-49$ \\
\hline (3) & myristoleic acid & C14:1(n-5) & $0.9 \pm 0.8$ & $1.6-4.5$ \\
\hline (4) & palmitic acid & $\mathrm{C} 16: 0$ & $653.2 \pm 165.3$ & $457 \simeq 882$ \\
\hline (5) & palmitoleic acid & $\mathrm{C} 16: 1 \mathrm{n}-7$ & $57.7 \pm 21$ & $28-93$ \\
\hline (6) & stearic acid & C18:0 & $201.6 \pm 50.1$ & $151 \simeq 258$ \\
\hline (7) & oleic acid & C18:1 n-9 & $647.9 \pm 202.2$ & $362 \sim 834$ \\
\hline (8) & linoleic acid & C18:2 n-6 & $756.3 \pm 156.2$ & $790 \simeq 1180$ \\
\hline (9) & $\gamma$-linolenic acid & C18:3 n-6 & $7.9 \pm 4.8$ & $2,8 \sim 15$ \\
\hline (10) & linolenic acid & C18:3n-3 & $22.6 \pm 8.3$ & $11-35$ \\
\hline (11) & arachidic acid & $\mathrm{C}: 20: 0$ & $2.8 \pm 2.4$ & $0.7 \simeq 2.9$ \\
\hline (12) & eicosenoic acid & $\mathrm{C} 20: 1 \mathrm{n}-9$ & $5.9 \pm 2.5$ & $2.5-8.2$ \\
\hline (13) & eicosadienoic acid & $\mathrm{C} 20: 2 \mathrm{n}-6$ & $5.2 \pm 1.3$ & $3.6 \simeq 7.2$ \\
\hline (14) & eicosatrienoic acid & C20:3 n-9 & $2 \pm 1.1$ & $0.8-2.8$ \\
\hline (15) & $\begin{array}{l}\text { dihomo- } \gamma \text {-linole- } \\
\text { nic acid }\end{array}$ & C20:3 n-6 & $31.6 \pm 11.9$ & $22-43$ \\
\hline (16) & arachidonic acid & C20:4 n-6 & $165.5 \pm 40.4$ & $113-166$ \\
\hline (17) & $\begin{array}{l}\text { eicosapentaenoic } \\
\text { acid }\end{array}$ & $C 20: 5 n-3$ & $69.9 \pm 42.1$ & $17-68$ \\
\hline (18) & behenic acid & $\mathrm{C} 22: 0$ & $5 \pm 6.6$ & $1.5 \simeq 3.6$ \\
\hline (19) & erucic acid & $\mathrm{C} 22: 1 \mathrm{n}-9$ & $1.1 \pm 0.6$ & $\sim 1.3$ \\
\hline (20) & $\begin{array}{l}\text { docosatetraenoic } \\
\text { acid }\end{array}$ & $\mathrm{C} 22: 4 \mathrm{n}-6$ & $3.6 \pm 1.7$ & $1.9-4.6$ \\
\hline (21) & $\begin{array}{l}\text { docosapentaenoic } \\
\text { acid }\end{array}$ & $\mathrm{C} 22: 5 \mathrm{n}-3$ & $17.9 \pm 5.6$ & $11-22$ \\
\hline (22) & lignoceric acid & $\mathrm{C} 24: 0$ & $4.7 \pm 6.2$ & -2.2 \\
\hline (23) & $\begin{array}{l}\text { docosahexaenoic } \\
\text { acid }\end{array}$ & $\mathrm{C} 22: 6 \mathrm{n}-3$ & $107.8 \pm 40.2$ & $56-109$ \\
\hline (24) & nervonic acid & $\mathrm{C} 24: 1 \mathrm{n}-9$ & $10.3 \pm 14.9$ & $1.2-3.8$ \\
\hline
\end{tabular}

(1) (24)areserial numbers for convienience.

Second, we examined the activity indices of elongase and desaturase. The synthetic pathway of long-chain fatty acids is shown in Figure 1. There were 18 combinations (12 elongation and 6 desaturation) within the 24 fatty acids measured. Significant correlations with VFA were found in estimated enzymatic activity indices of palmitoleic acid (C16:1 n-7, 5) / palmitic acid (C16:0, (4) $(\mathrm{r}=0.719, \mathrm{p}<0.001)$, stearic acid $(\mathrm{C} 18: 0$, (6) $/$ palmitic acid $(\mathrm{C} 16: 0$, (4) $)(\mathrm{r}=-0.495, \mathrm{p}=0.004)$,oleic acid (C18:1 n-9, (7) / stearic acid (C18:0,6) $(\mathrm{r}=0.534, \mathrm{p}=0.002)$, eicosenoic acid (C20:1 n-9, (12) / oleic acid (C18:1 n-9, 7) (r $=-0.435, \mathrm{p}=0.013)$, and arachidonic acid $(\mathrm{C} 20: 4 \mathrm{n}-6$, (16) / dihomo- $\gamma$-linolenic acid (C20:3 n-6, (15) $(r=-0.416, p=0.018)$. Scatter plots show the factors with higher correlations $(r>0.45)$ with VFA as follows : palmitoleic acid (C16:1 n-7, 5) (Figure 2A), palmitoleic acid (C16:1 n-7, 5) / palmitic acid (C16:0, (4) (Figure 2B), stearic acid (C18:0, 6) / palmitic acid (C16:0, (4) (Figure 2C), and oleic acid (C18:1 n-9, (7) / stearic acid (C18:0, (6)) (Figure 2D). The data highlighted the reciprocal associations of VFA with SCD-1 and Elovl6 indexes. 
Citation: Yatoh, S., et al. Estimated Stearoyl-CoA-desaturase (SCD)-1 and Elongase of Very Long Chain Fatty Acids (Elovl) 6 Activities From Serum Fatty Acids Are Reciprocally Associated with Visceral Fat Area in Type 2 Diabetic Patients. (2018) J diab Obes 5(1): 41- 47.

Table 3: Correlations of VFA with fatty acid concentrations and estimated activity indices of elongases or desaturases.

\begin{tabular}{|c|c|c|c|c|}
\hline \multirow{2}{*}{\multicolumn{2}{|c|}{ fatty acid }} & \multirow{2}{*}{ abbreviation } & \multicolumn{2}{|c|}{ vs VFA } \\
\hline & & & $r$ & $\mathrm{p}$ \\
\hline (1) & lauric acid & $\mathrm{C} 12: 0$ & 0.094 & $>0.05$ \\
\hline (2) & myristic acid & $\mathrm{C} 14: 0$ & 0.139 & $>0.05$ \\
\hline (3) & myristoleic acid & $\mathrm{C} 14: 1(\mathrm{n}-5)$ & 0.184 & $>0.05$ \\
\hline (4) & palmitic acid & $\mathrm{C} 16: 0$ & 0.231 & $>0.05$ \\
\hline (5) & palmitoleic acid $*$ & $\mathrm{C} 16: 1 \mathrm{n}-7$ & 0.565 & 0.001 \\
\hline (6) & stearic acid & $\mathrm{C} 18: 0$ & -0.057 & $>0.05$ \\
\hline (7) & oleic acid & C18:1 n-9 & 0.267 & $>0.05$ \\
\hline (8) & linoleic acid & $\mathrm{C} 18: 2 \mathrm{n}-6$ & 0.024 & $>0.05$ \\
\hline (9) & $\gamma$-linolenic acid & C18:3 n-6 & 0.219 & $>0.05$ \\
\hline (10) & linolenic acid & $\mathrm{C} 18: 3 \mathrm{n}-3$ & -0.017 & $>0.05$ \\
\hline (11) & arachidic acid $*$ & C:20:0 & -0.351 & 0.049 \\
\hline (12) & eicosenoic acid & C20:1 n-9 & -0.189 & $>0.05$ \\
\hline (13) & eicosadienoic acid & $C 20: 2 n-6$ & 0.054 & $>0.05$ \\
\hline (14) & eicosatrienoic acid & $\mathrm{C} 20: 3 \mathrm{n}-9$ & -0.183 & $>0.05$ \\
\hline (15) & dihomo- $\gamma$-linolenic acid & $\mathrm{C} 20: 3 \mathrm{n}-6$ & 0.321 & $>0.05$ \\
\hline (16) & arachidonic acid & $\mathrm{C} 20: 4 \mathrm{n}-6$ & 0.067 & $>0.05$ \\
\hline (17) & eicosapentaenoic acid & $\mathrm{C} 20: 5 \mathrm{n}-3$ & -0.225 & $>0.05$ \\
\hline 18 & behenic acid & $\mathrm{C} 22: 0$ & -0.301 & $>0.05$ \\
\hline (19) & erucic acid & $\mathrm{C} 22: 1 \mathrm{n}-9$ & -0.238 & $>0.05$ \\
\hline (20) & docosatetraenoic acid & $\mathrm{C} 22: 4 \mathrm{n}-6$ & 0.041 & $>0.05$ \\
\hline (21) & docosapentaenoic acid & $\mathrm{C} 22: 5 \mathrm{n}-3$ & -0.178 & $>0.05$ \\
\hline (22) & lignoceric acid & $\mathrm{C} 24: 0$ & -0.293 & $>0.05$ \\
\hline (23) & docosahexaenoic acid & $\mathrm{C} 22: 6 \mathrm{n}-3$ & -0.251 & $>0.05$ \\
\hline (24) & nervonic acid & $\mathrm{C} 24: 1 \mathrm{n}-9$ & -0.294 & $>0.05$ \\
\hline \multicolumn{2}{|c|}{ index of elongase or desaturase } & emzyme & $\mathrm{r}$ & $\mathrm{p}$ \\
\hline \multirow[t]{12}{*}{$\mathrm{n}-9$} & (2)/(1) & Elovl6 & -0.086 & $>0.05$ \\
\hline & (3)/2) & & 0.137 & $>0.05$ \\
\hline & (4)/2) & Elovl6 & 0.395 & $>0.05$ \\
\hline & (5)/4)* & SCD-1(16) & 0.719 & $<0.001$ \\
\hline & (6)/4)* & Elov16 & -0.495 & 0.004 \\
\hline & (11)/6) & Elovl3 & -0.318 & $>0.05$ \\
\hline & (18/(11) & Elovl1, 3 & -0.079 & $>0.05$ \\
\hline & (22)/ 18 & Elovl1 & 0.285 & $>0.05$ \\
\hline & (7)/6)* & SCD-1(18) & 0.534 & 0.002 \\
\hline & (12)/7)* & Elovl3 & -0.435 & 0.013 \\
\hline & (19)/12 & Elovl1 & -0.081 & $>0.05$ \\
\hline & (24)/(19) & Elovl1 & -0.144 & $>0.05$ \\
\hline \multirow[t]{4}{*}{$n-6$} & (9)/8) & D6D & 0.171 & $>0.05$ \\
\hline & (15)/9) & Elov15 & 0.007 & $>0.05$ \\
\hline & (16)/(15)* & D5D & -0.416 & 0.018 \\
\hline & (20/(16) & Elov15 & 0.037 & $>0.05$ \\
\hline \multirow[t]{2}{*}{$n-3$} & (21)/17) & Elov15 & 0.05 & $>0.05$ \\
\hline & (23)/(21) & D6D & -0.117 & $>0.05$ \\
\hline
\end{tabular}

r: correlation coefficient

Elovl: elongaion of very long chain fatty acids

SCD-1: stearoyl-CoA-desaturase-1 (D9D)

D9 $(, 6$, or 5) D: D9 $(, 6$, or 5) desaturase $* \mathrm{p}<0.05$

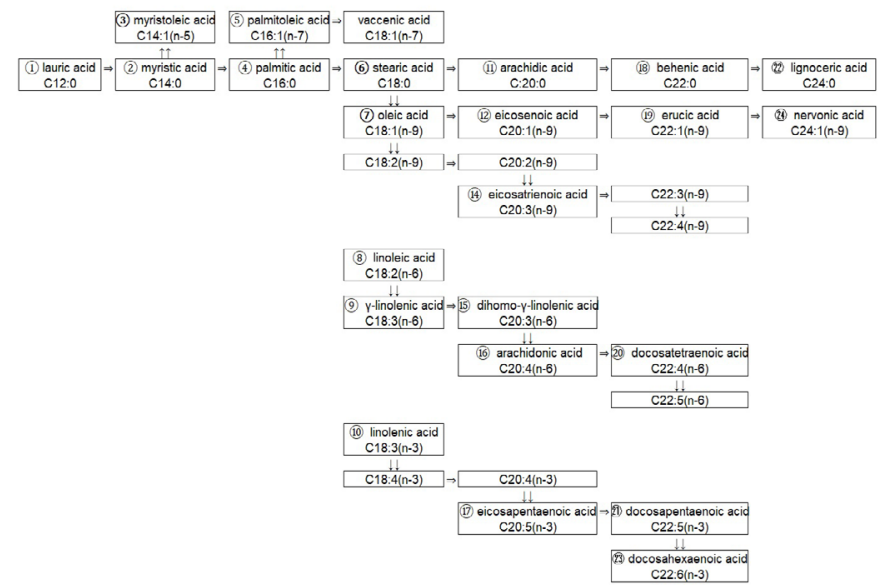

Figure 1: Synthetic pathway of long-chain fatty acids

$\Rightarrow$ : elongation

$\downarrow \downarrow$ : desaturation

(1)-(24): serial numbers for ease of identification of fatty acids that were measured in this study.

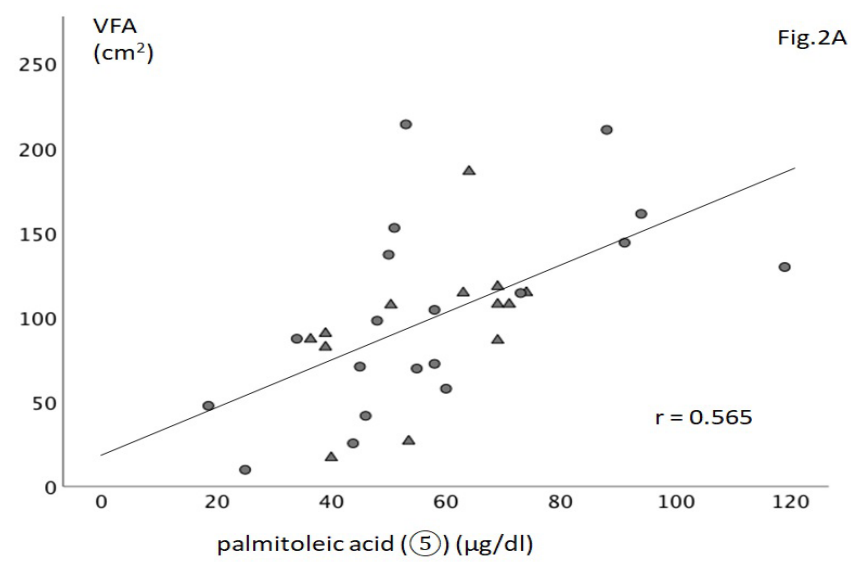

2A: palmitoleic acid (5)

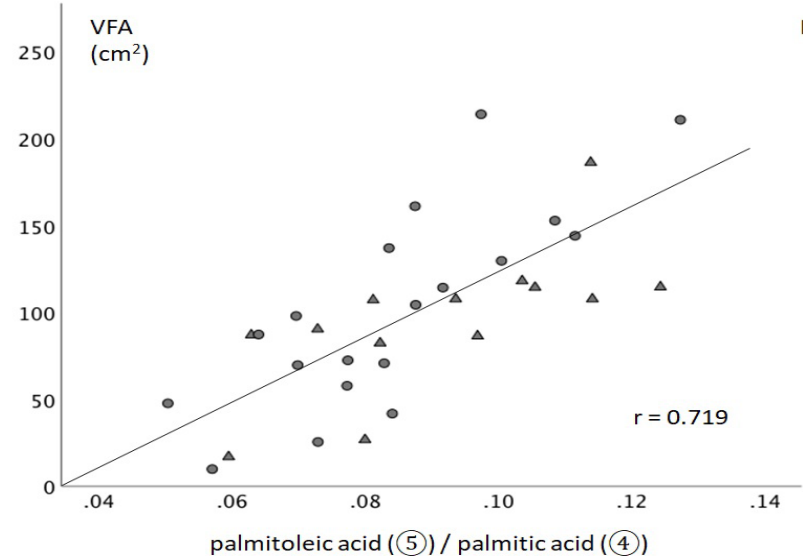

2B: palmitoleic acid (5) / palmitic acid (4);

VFA: visceral fat area 


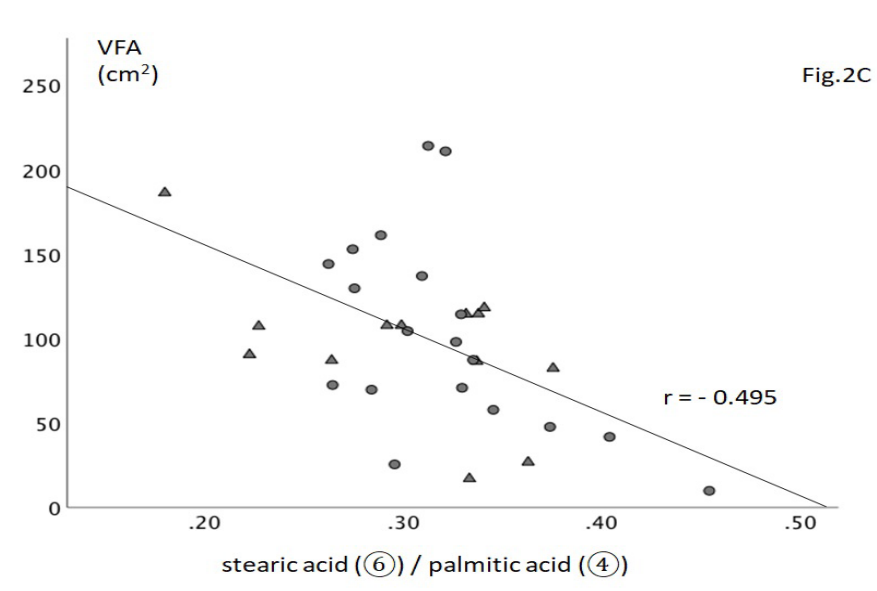

2C: stearic acid (6) / palmitic acid (4);

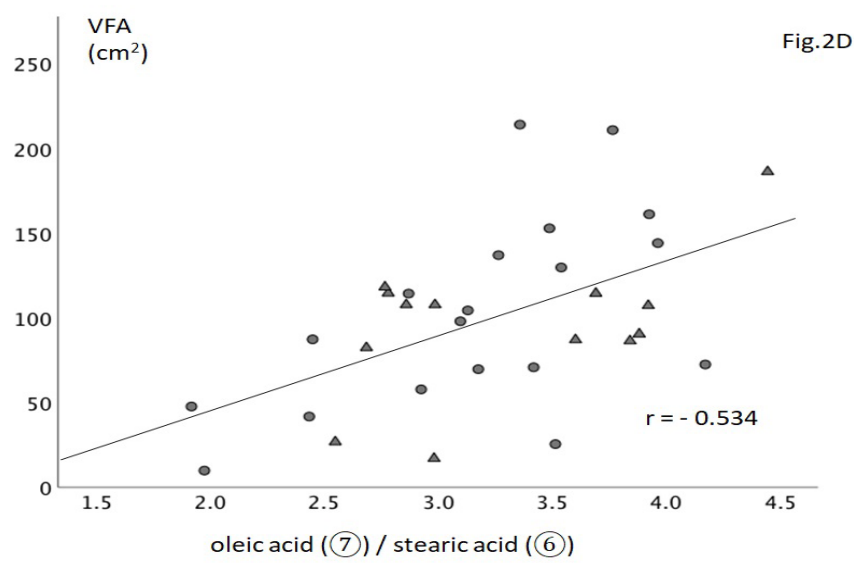

2D: oleic acid (7) / stearic acid (6)

Figure 2: Correlations with visceral fat area

Closed circles: men; Closed triangles: women

The regression line is shown in each figure

\section{Discussion}

VFA is one of the important factors to be considered with regard to insulin resistance in patients with type 2 diabetes and/or metabolic syndrome. We hypothesized that there might be some relationship between the accumulation of visceral fat and serum fatty acid levels because adipocytes could release fatty acids into blood. Unexpectedly, in this study, only the serum palmitoleic acid (C16:1 n-7, 5) level had a moderately positive correlation $(r=0.565)$ with VFA. The arachidic acid (C:20:0, (11) level had a very weak negative correlation $(r=-0.351)$ and the other 22 fatty acids had no significant correlations.

On the other hand, we discovered five significant correlations among the 18 estimated activity indices of elongases and desaturases. Four were in n-9 fatty acids and one was in n-6 fatty acids. Positive correlations were found in two desaturases (n-9), and negative correlations were seen in two elongases (n-9) and one desaturase (n-6).

We focused on the palmitoleic acid (5) level and the three activity indices (palmitoleic acid (C16:1 n-7, 5) / palmitic acid (C16:0, (4), stearic acid (C18:0, 6) / palmitic acid (C16:0, (4)), and oleic acid (C18:1 n-9, (7) / stearic acid (C18:0, 6)) that showed stronger correlations $(r>0.450)$ with VFA. Scatter plots (Figure 2A-D) indicated good correlations between each of these factors and VFA (Figure 2A-D), with palmitoleic acid
(C16:1 n-7, (5) / palmitic acid (C16:0, (4) having the best correlation (Figure $2 \mathrm{~B}$ ).

For ease of identification, we used the following designations as shown in parentheses: palmitoleic acid (C16:1 n-7, (5) / palmitic acid (C16:0, (4)), oleic acid (C18:1 n-9, (7) / stearic acid (C18:0, (6), and stearic acid (C18:0, 6) / palmitic acid (C16:0, (4) as the SCD-1(16) index, SCD-1(18) index, and Elovl6 index, respectively. SCD-1 converts both desaturations ofpalmitic acid $(\mathrm{C} 16: 0$, (4) $)$ to palmitoleic acid $(\mathrm{C} 16: 1 \mathrm{n}-7$, (5)) and stearic acid (C18:0, (6) to oleic acid (C18:1 n-9, (7)), distinguishing them with the carbon number of the fatty acids as the estimated index.

We tried to consider the mechanism of these correlations through information provided in previous reports. It is well known that fatty acid compositon is highly associated between blood and liver. For example, Kotronen et al. ${ }^{[16]}$ reported close relationships of values for the SCD-1(16), SCD-1(18), and Elovl6 indices between those in the serum and liver in eight human subjects. Interestingly, no such relationships were found between those indices and intra-abdominal and subcutaneous fat. Considering that enzyme activities responsible for plasma indexes are attributed to be primarily from the liver, these current indices in serum might reflect those in liver rather than those from adipose tissues. Conversely, a thought-provokingly report showed that production of oleate in the liver confers changes in fatty acid metabolism in adipose tissues through an elegant establishment of mice with a combination of genetic modifications of SCDs, indicating that hepatic lipogenesis could modify adiposity ${ }^{[17]}$. Although the precise mechanism is still unclear, the close association of visceral fats and fatty acid composition in plasma or liver implicates the presence of organ cross talk on fatty acid and energy metabolism.

On the other hand, Tan et al. ${ }^{[18]}$ reported that in mouse models, the Elovl6 ratio in triglycerides of subcutaneous white adipose tissue was associated with insulin sensitivity, whereas the SCD-1 ratio was associated with fat mass. These intriguing findings were based on calculations in a more complex way that was different from ours considering the potential mutual influences on values of indexes because Elovl6 and SCD-1 reactions are consecutive for $n-9$ and n-7 fatty acids. Therefore, they defined the SCD-1 ratio as (vaccenic acid (C18:1n-7) + oleic acid (C18:1 n-9, (7) + palmitoleic acid (C16:1 n-7, 5)) / (palmitic acid $(\mathrm{C} 16: 0,(4))+$ stearic acid $(\mathrm{C} 18: 0$, (6)) $)$ and the Elovl6 ratio as (stearic acid $(\mathrm{C} 18: 0,6)+$ vaccenic acid $(\mathrm{C} 18: 1 \mathrm{n}-7)+$ oleic acid (C18:1 n-9, (7)) / ((palmitic acid $(\mathrm{C} 16: 0$, (4) $)+$ palmitoleic acid (C16:1 n-7, (5))). Although the concentration of vaccenic acid (C18:1 n-7) was not determined in our study, we tried to calculate their SCD-1 ratio and Elovl6 ratio for reference to consider the concentration of vaccenic acid (C18:1 n-7) as zero. As a result, this SCD-1 ratio still showed a signifiant positive correlation $(r=0.437, p=0.012)$ with VFA, a marker of fat mass, but the new Elovl6 ratio lost the significant correlation. It could be speculated that high SCD-1 activity with efficient conversion of stearic acid (C18:0, (6) to oleic acid (C18:1 n-9, (7) might contribute to the low Elovl6 ratio resulting from lower stearic acid (C18:0, (6)). Palmitoleic acid (C16:1 n-7, (5) concentration solely showed a significant correlation with VFA, potentially reflecting high SCD-1 activity and/or low Elovl6 activity for n-7 fatty acids, although Elovl5 could also contribute to this reac- 
Citation: Yatoh, S., et al. Estimated Stearoyl-CoA-desaturase (SCD)-1 and Elongase of Very Long Chain Fatty Acids (Elovl) 6 Activities From Serum Fatty Acids Are Reciprocally Associated with Visceral Fat Area in Type 2 Diabetic Patients. (2018) J diab Obes 5(1): 41- 47.

tion. These speculations might adversly affect the role of hepatic Elovl6 on obesity and insulin resistance reported in our previous mouse study ${ }^{[5]}$ from the standpoint of human plasma fatty acid levels. However, further studies with precise estimation of cis-vaccenic acid (CVA) is required to conclude how plasma Elovl6 indices reflect the story of hepatic Elovl6 and pathology.

Loss of SCD-1 function is protective against obesity in mouse model. The decreased adiposity in SCD-1 knock-out mice was caused by reduced lipid synthesis and increased enery expenditure through enhanced fatty acid oxidation ${ }^{[19]}$. Insulin signaling and glucose uptake in muscle and brown adipose tissue were increased ${ }^{[20,21]}$. In human, it was reported that higher estimated activity of SCD-1 in serum predicted development of metabolic syndrome in men ${ }^{[22,23]}$. These reports support our current data.

Though somehow implicative, we cannot evaluate their associations with insulin sensitivity/resistance because fasting plasma glucose levels were more than $140 \mathrm{mg} / \mathrm{dL}$ in most of our study cases. The homeostasis model assessment of insulin resistance (HOMA-IR), which is calculated with fasting levels of glucose and insulin, is a good marker of insulin resistance when fasting glucose levels are equivalent to or less than $140 \mathrm{mg} / \mathrm{dL}$ but it is not when values are greater than $140 \mathrm{mg} / \mathrm{mL}$.

As already mentioned, a limitation of our study is that concentrations of vaccenic acid (C18:1 n-7) were not measured. Unfortunately, methods for measurement of fatty acid concentrations that Japanese health insurance cover do not quantify the amount of vaccenic acid (C18:1 n-7), though those methods can distinguish between vaccenic acid (C18:1 n-7) and oleic acid (C18:1 n-9, (7)). A distinct association was observed for the palmitoleic acid (C16:1 n-7, (5) /palmitic acid (C16:0, (4) SCD-1(16) index and adiposity, suggesting that the n-7 lipogenesis palmitoleic acid-pathway might be potentially important in relation to obesity and diabetes.

\section{Conclusion}

In conclusion, we can consider the serum SCD-1(16) index to be a useful marker to estimate visceral fat accumulation. In obese or insulin-resistant type 2 diabetic patients, the amount of visceral fat should change through diet, exercise, and usage of sodium-glucose co-transporter 2 inhibitors. Because computed tomography presents the risk of radiation exposure, it is not appropriate for multiple evaluations to determine the VFA overtime.

Acknowledgement: This work was supported by JSPS KAKENHI Grant Number JP25350836.

Disclosure: The authors declared no conflict of interest.

\section{References}

1. Stumvoll, M. Control of glycaemia: from molecules to men. Minkowski Lecture 2003. (2004) Diabetologia 47(5): 770781.

Pubmed | Crossref | Others

2. Warensjo, E., Riserus, U., Vessby, B. Fatty acid composition of serum lipids predicts the development of the metabolic syndrome in men. (2005) Diabetologia 48(10): 1999-2005.

Pubmed | Crossref | Others

3. Ohrvall, M., Berglund, L., Salminen, I., et al. The serum cholesterol ester fatty acid composition but not the serum concentration of alpha tocopherol predicts the development of myocardial infarction in 50-year-old men: 19 years follow-up. (1996) Atherosclerosis 127(1): 65-71.

Pubmed | Crossref | Others

4. Corpeleijn, E., Feskens, E.J., Jansen, E.H., et al. Improvements in glucose tolerance and insulin sensitivity after lifestyle intervention are related to changes in serum fatty acid profile and desaturase activities: the SLIM study. (2006) Diabetologia 49(10): 2392-2401.

Pubmed | Crossref | Others

5. Matsuzaka, T., Shimano, H., Yahagi, N., et al. Crucial role of a long-chain fatty acid elongase, Elovl6, in obesity-induced insulin resistance. (2007) Nat Med 13: 1193-1202.

Pubmed | Crossref | Others

6. Matsuzaka, T., Shimano, H., Yahagi, N., et al. Cloning and characterization of a mammalian fatty acyl-CoA elongase as a lipogenic enzyme regulated by SREBPs. (2002) J Lipid Res 43(6): 911-920.

Pubmed | Crossref | Others

7. Kumadaki, S., Matsuzaka. T., Kato, T., et al. Mouse Elovl-6 promoter is an SREBP target. (2008) Biochem Biophys Res Commun 368(2): 261-266.

Pubmed | Crossref | Others

8. Morcillo, S., Martin-Nunez, G.M., Rojo-Martinez, G., et al. ELOVL6 genetic variation is related to insulin sensitivity: a new candidate gene in energy metabolism. (2011) PLOS One 6(6): e21198.

Pubmed | Crossref | Others

9. Liu, Y., Wang, F., Yu ,X.L., et al. Genetic analysis of the ELOVL6 gene poly- morphism associated with type 2 diabetes mellitus. (2013) Braz J Med Biol Res 46(7): 623-628. Pubmed | Crossref | Others

10. Saito, R., Matsuzaka, T., Karasawa, T., et al. Macrophage Elovl6 deficiency ameliorates foam cell formation and reduces atherosclerosis in low-density lipoprotein receptordeficient mice. (2011) Arterioscler Thromb Vasc Biol 31(9): 1973-1979.

Pubmed | Crossref | Others

11. Kuba, M., Matsuzaka, T., Matsumori, R., et al. Absence of Elovl6 attenuates steatohepatitis but promotes gallstone formation in a lithogenic diet-fed Ldlr(-/-) mouse model. (2015) Sci Rep 5: 17604.

Pubmed | Crossref | Others

12. Matsuzaka, T., Atsumi, A., Matsumori, R., et al. Elovl6 promotes nonalcoholic steatohepatitis. (2012) Hepatology 56(6): 2199-2208.

Pubmed | Crossref | Others

13. Sunaga, H., Matsui, H., Ueno, M., et al. Deranged fatty acid composition causes pulmonary fibrosis in Elovl6-deficient 
mice. (2013) Nat Commun 4: 2563.

Pubmed | Crossref | Others

14. Sunaga, H., Matsui, H., Anjo, S., et al. Elongation of LongChain Fatty Acid Family Member 6 (Elovl6)-Driven Fatty Acid Metabolism Regulates Vascular Smooth Muscle Cell Phenotype Through AMP-Activated Protein Kinase/Krüppel-Like Factor 4 (AMPK/KLF4) Signaling. (2016) J Am Heart Assoc 5: e004014.

Pubmed | Crossref | Others

15. Kikuchi, M., Shimada, M., Matsuzaka, T., et al. Crucial Role of Elovl6 in Chondrocyte Growth and Differentiation during Growth Plate Development in Mice. (2016) PLoS One 11(7): e0159375.

Pubmed | Crossref | Others

16. Kotronen, A., Seppänen-Laakso, T., Westerbacka, J., et al. Comparison of lipid and fatty acid composition of the liver, subcutaneous and intra-abdominal adipose tissue, and serum. (2011) Obesity 18: 937-944.

Pubmed | Crossref | Others

17. Burhans, M.S., Flowers, M.T., Harrington, K.R., et al. Hapatic oleate regulates adipose tissue lipogenesis and fatty acid oxidation. (2015) J Lipid Res 56(2): 304-318.

Pubmed | Crossref | Others

18. Tan, C.Y., Virtue, S., Murfitt, S., et al. Adipose tissue fatty acid chain length and mono-unsaturation increases with obesity and insulin resistance. (2015) Sci Rep 5: 18366.

Pubmed | Crossref | Others
19. Ntambi, J.M., Miyazaki, M., Stoehr, J.P., et al. Loss of stearoyl-CoA desaturase-1 function protects mice against adiposity. (2002) Proc Natl Acad Sci U S A 99(17): 1148211486.

Pubmed | Crossref | Others

20. Rahman, S.M., Dobrzyn, A., Dobrzyn, P., et al. Stearoyl-CoA desaturase 1 deficiency elevates insulin-signaling components and downregulates protein-tyrosine phosphatase 1B in muscle. (2003) Proc Natl Acad Sci U S A 100: 11110-11115.

Pubmed | Crossref | Others

21. Rahman, S.M., Dobrzyn, A., Lee, S.H., et al. Stearoyl-CoA desaturase 1 deficiency increases insulin signaling and glycogen accumulation in brown adipose tissue. (2005) Am J Physiol Endocrinol Metab 288: E381-E387.

Pubmed | Crossref | Others

22. Kawashima, A., Sugawara, S., Okita, M., et al. Plasma fatty acid composition, estimated desaturase activities, and intakes of energy and nutrient in Japanese men with abdominal obesity or metabolic syndrome. (2009) J Nutr Sci Vitaminol 55(5): 400-406.

Pubmed | Crossref | Others

23. Warensjö, E., Risérus, U., Vessby, B. Fatty acid composition of serum lipids predicts the development of the metabolic syndrome in men. (2005) Diabetologia 48(10): 1999-2005.

Pubmed | Crossref | Others
Submit your manuscript to Ommega Publishers and we will help you at every step:

- We accept pre-submission inquiries

- Our selector tool helps you to find the most relevant journal

- We provide round the clock customer support

- Convenient online submission

- Thorough peer review

- Inclusion in all major indexing services

- Maximum visibility for your research

Submit your manuscript at

https://www.ommegaonline.org/submit-manuscript 